\title{
Huzhou Urban Landscape Sketch Design Based on the Charm of Historical and Cultural Cities
}

\author{
Ziqi Yang \\ Art School \\ Huzhou University \\ Huzhou, China 313000
}

\begin{abstract}
The urbanization construction has brought many emerging small and medium-sized cities like Huzhou to rise, which has brought a rare opportunity for the development of urban landscape sketch. However, a series of problems arising from the rapid development of urban construction are more and more prominent. Protecting historical and cultural cities, inheriting outstanding national culture, and highlighting the charm of historical and cultural cities are important parts of creating a "Humanistic Huzhou". Historical and cultural city landscape sketch design should standardize the implementation system, integrate local culture, improve aesthetic taste, respect the democratic rights of the masses, highlight the historical and cultural characteristics of the famous city, embody the urban spirit of the historical and cultural city, and reveal public thoughts.
\end{abstract}

Keywords-historical and cultural city; Huzhou; landscape sketch design; regional culture; aesthetic taste

\section{INTRODUCTION}

Marxism believes that the city is the starting point and main symbol of the era of human civilization. The emergence of cities is the inevitable development of human history and plays a more important role in the progress of human civilization. The history of urban development is the most abundant and concentrated core part of human history. The "historical and cultural city" was the national economic and cultural center at that time, and it was the gathering place of civilization and wealth. Each of them was born with its unique fertile soil. It had breed splendid national culture, and became a gathering place for the essence of national civilization.

In the reply (Letter of the State [2014] No. 88), the State Council pointed out that Huzhou had long history and rich heritage. The cultural landscape of Lougang Irrigation and Drainage System of Taihu Lake Basin is outstanding. The traditional pattern and style of the city are well preserved, which has important historical and cultural values. At present, protecting historical and cultural cities, inheriting outstanding national culture, and highlighting the charm of historical and cultural cities are important parts of creating a "Humanistic Huzhou". The famous architect Mies van der Rohe once said: "The life of the city lies in the details." That is to say, the embodiment of charm should focus on the details. The landscape sketch is the most important part of the city details. It is used for people's use. Also, it has the visual aesthetic. The landscape sketch of historical and cultural cities not only carries the cultural memory of the city, but also presents the city's contemporary atmosphere and aesthetic character. They play a decisive role in improving the urban humanities and art environment, strengthening urban differences, and building urban image. The design of landscape sketch is important.

\section{THE URBAN LANDSCAPE SKETCH}

Urban landscape sketch is the general term for various landscape elements. At present, the landscape sketch we define are broadly understood, that is, small artificial objects that are different from large buildings, rocks, water surfaces and greening elements. The landscape sketch consists of three parts: architectural sketch, living facility sketch and road facility sketch, including sculptures, murals, art installations, seats, telephone booths, signs, lamps, garbage cans, fitness, gaming facilities, building doors and windows, decorative lights, house number, etc. The urban landscape sketch enriches the content of urban space, affects the image of urban space, reflects the unique landscape and humanity of a city, shows the temperament and style of the city, and the economic situation of the city. It is the symbol of social development and national civilization. Urban landscape sketches promote harmonious dialogue between people and the urban environment, and help people to interact with each other naturally. It is an important part for enriching citizens' lives and improving city quality.

\section{THE MAIN FEATURES OF THE HISTORICAL AND Cultural City LANDSCAPE SKetch}

\section{A. Regionality}

Today, with the global urbanization, the landscape sketches of historical and cultural cities pay more and more attention to the role of regional culture in urban construction. Due to the differences in urban culture, modern landscape sketches are bound to exhibit complex and diverse characteristics. As the French art theorist Danner said in "Art Philosophy": "The spiritual aspect also has its feature. Its changes determine the emergence of this or that kind of art. We study the natural climate to understand the emergence of certain plants... Similarly, we should study the spiritual 
climate to understand the emergence of certain art... The products of spiritual civilization are the same as the animals and plants. It can be explained from the respective of its own environment." Therefore, the landscape sketches of historical and cultural cities should be rooted in the specific environment. Influenced by the regional culture, the city's topography, history, context and citizen's temperament are vividly shaped. The sculpture of Yan'an Railway Station Square reflects this local culture (see "Fig. 1"). Of course, the architectural design of the railway station also uses local cave dwelling styles. The recognition for people is highly unified and holistic. In addition, the Suzhou City Bus Station (see "Fig. 2") and the Wuzhen Expressway Toll Station (see "Fig. 3") are consistent with the regional culture in the design.

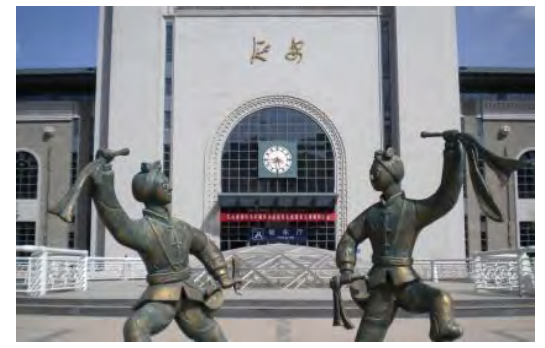

Fig. 1. The sculpture of Yan'an Railway Station Square.

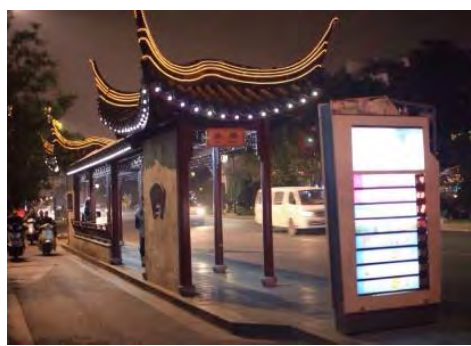

Fig. 2. Suzhou City Bus Station.

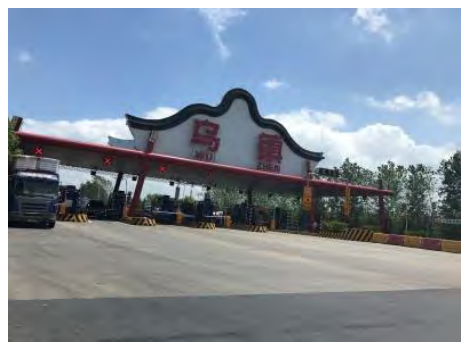

Fig. 3. Wuzhen Expressway Toll Station.

\section{B. Publicity}

The publicity of landscape sketch includes public space and participation. Its publicity is the embodiment of the development of human civilization and the appeal of human design art. It conveys the attitude of design art to the public and expresses the democratic ideas of art in an open, communication and shared way. The design of landscape sketch takes the interaction among urban society, some natural physical environment and public communication as an important aspect of its original intention, and makes the city establish a lively, close-knit and vivid way of viewing. The subject/object interface between the public and the landscape is diminished. The public can freely access, touch, snuggle, and even climb to the landscape sketch, which will ease the suppression and rejection of urban high-density, high-rise buildings on people. It has become a public life art.

\section{The Status Quo of Huzhou Urban Landscape SKETCHES}

Small landscapes also need great wisdom. In addition to a few of excellent works recognized by the public, most of Huzhou urban landscape works often ignore the spiritual functions. The quality is low, which seriously affects the image of the city. Some art works are separated from the public life. They are also used for the commercial purposes, blindly pursuing economic benefits. The form of the work is single, lacking the individuality. The design level of Huzhou urban landscape sketches is uneven. The landscape sketch items such as garbage bins, leisure chairs, kiosks, bus stops, street lights, signposts, sculptures, etc. are lack of design and symbolic representations of Huzhou history and culture. It is difficult to distinguish the historical heritage of this city from that of other cities through intuitive landscape markers. It does not reflect the local traditional customs and urban expressions, neglecting the artistic symbol design of the historical context of the landscape.

\section{THE DEVELOPMENT TREND OF HUZHOU URBAN LANDSCAPE SKETCH DESIGN}

\section{A. Standardizing the Implementation System of Landscape Sketches}

Today, the implementation organization of Huzhou urban landscape sketch is still not perfect. There is no special construction fund. The market is chaotic, and even individual undertakes the projects, resulting in the proliferation of "urban waste". Some builders have low quality, and they determine the projects and location independently. It is not in harmony with the environment. With the development of the city, and the progress of the society, the development of landscape sketch is the need of the times, and the inevitability of history. The standardization of the implementation system of Huzhou urban landscape sketch is imminent. We can regulate the development of landscape sketch in Huzhou, a historical and cultural city, from the establishment of management institutions, the implementation of the approval system, and the establishment of the "one percent public cultural plan".

\section{B. Further Exploring Regional Cultural Content}

The humanistic traits of the historical and cultural city landscape sketch are interdependent with the urban temperament and style. Excellent landscape sketch can play a finishing touch to historical and cultural cities, and the combination of urban landscape sketch and urban culture can reflect the characteristics of a city. The historical and cultural city landscape sketch incorporate rich historical and cultural heritage. This can highlight the historical and humanistic characteristics of the famous city, reflect the urban spirit of the historical and cultural city, and expose the public mind. "Jiangnan has rich heritage, and Huzhou is beautiful." 
Huzhou has good ecological environment and profound historical and cultural heritage. Half the history of Chinese calligraphy and painting is about Huzhou city. Huzhou is the birthplace of the Huzhou writing brush, the birthplace of silk culture, the birthplace of tea culture, the prosperity of "Huzhou knowledge" and the gathering place of cultural celebrities. We should excavate a group of local representative cultures and create distinctive works with distinctive features to consolidate urban characteristics and improve the differences among the cities.

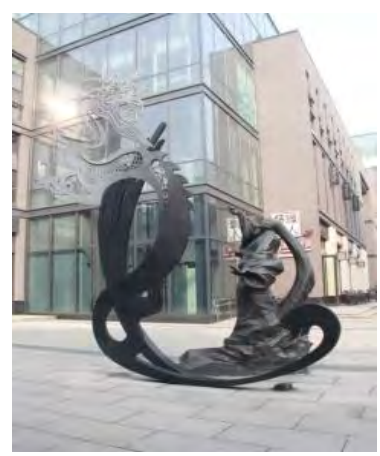

Fig. 4. "Adding the Finishing Touch".

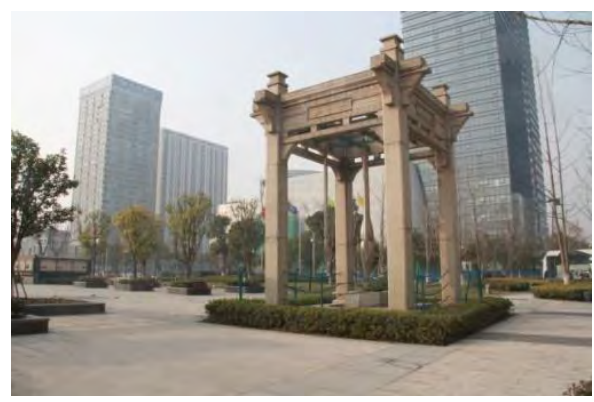

Fig. 5. "Pen Pavilion".
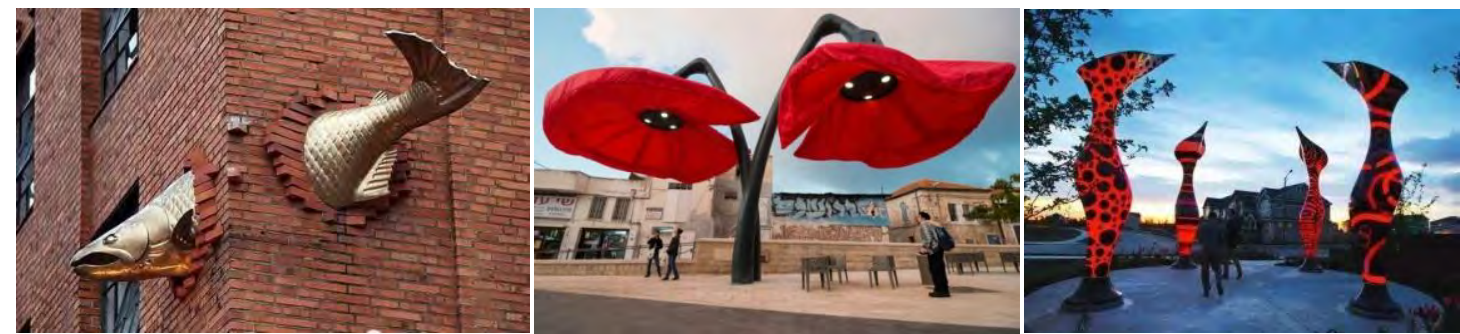

Fig. 7. Huzhou Landscape sketch.

Landscape sketches are mostly traditional in terms of materials, colors, techniques, scales, etc., and their presentation forms are relatively simple (see "Fig. 7"). Landscape sketch is an important carrier for the characteristics of the urban era. It is a concrete manifestation of the humanization of the urban environment, and a product of social progress and the concept of the times. The forms of landscape sketch should use the latest design ideas and concepts as much as possible, emphasizing the originality and diversity. It should strive to enhance the aesthetic taste of art on the basis of satisfying the use functions, and add elements such as multimedia, installation, film and television, and behavior to make it easy, cheerful, fashionable and

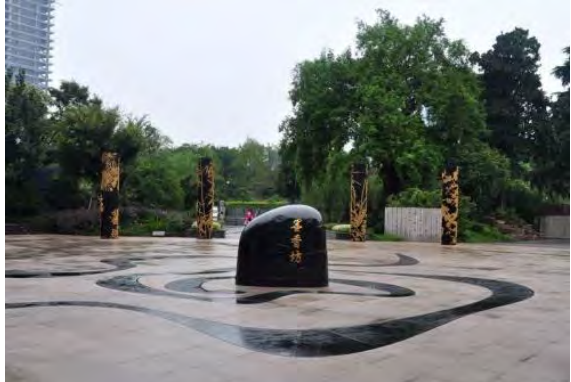

Fig. 6. "Ink Rhyme".

The works such as "Adding the Finishing Touch"(see "Fig. 4"), "Pen Pavilion" (see "Fig. 5") and "Ink Rhyme" (see "Fig. 6") in Aishan Square are created with the content of "writing brush and ink culture", which have strong local cultural characteristics. However, there is still a large room for expansion in the number and theme of the exhibits. After all, the scattered embellishment is not enough for the overall appearance.

\section{Enhancing the Aesthetic Taste of Art}

Huzhou has long history and rich cultures. It has been rich since the ancient times, and has slow pace of life. The development of urban landscape sketch is relatively conservative. 
overall coordination between individual landscape sketches within a region. The landscape sketch portfolio in this region must also conform to the historical and cultural characteristics and spiritual character of the entire city, which means that the landscape sketches are subject to the overall interests of the environment. It should strengthen the concept of global planning and clarify the relationship between the master and the slave, instead of just considering their individuality.

\section{E. Respecting the Democratic Rights of the Public}

The construction of urban landscape sketches is to beautify the urban environment, enrich the cultural life of the masses, and reflect the public democratic rights. It is closely related to the lives of the masses. Therefore, in the creation of Huzhou urban landscape sketch, we must respect the public's rights. The public needs what kind of landscape sketch. As the decision maker, they can't avoid the problem. In order to meet the cultural needs, aesthetic needs, historical care, customs and habits of the public in the new cultural context, the contemporary landscape sketch of Huzhou City is set to reflect the public spirit, universal consciousness, and publicity. That is the public purpose. Designers can express rich personal feelings. However, they focus on expressing the will of the public, including some publicistic ideas, cultural concepts, local characteristics, customs and other public spirits formed in Huzhou history.

\section{CONCLUSION}

The historical and cultural city is a city with rich cultural relics, profound cultural heritage, great historical and cultural values and revolutionary significance. Its unique historical culture is gradually formed and developed in the process of social development. The landscape sketch of historical and cultural cities should consider the application of history and culture in the design. The design of Huzhou urban landscape sketches should effectively select representative historical and cultural contents according to the block, refine the artistic language symbols reflecting the characteristics of Huzhou historical and cultural cities, and apply the latest design ideas and concepts to integrate the historical and cultural characteristics of the city, urban spiritual character and urban landscape sketch design. Thus, it will create a batch of works with high historical and cultural recognition. At the same time, it can inherit the historical details and diversified cultural heritage of the city. In continuing the traditional connotation and creating the modern informationized life quality, it creates the culture foundation of humanistic characteristic city, revealing the charm of Huzhou historical and cultural city.

\section{REFERENCES}

[1] Wang Qiming. Application of landscape facilities in urban landscape [J] Heritage Architecture, 2013. (in Chinese)

[2] Yang Ziqi. Research on the identifiability design of urban landscape s ketch [J] Sichuan Theatre, 2013. (in Chinese)

[3] Yang Ziqi. Discussion on the constituent elements of landscape desig $\mathrm{n}$ - sculpture [J] Art Education, 2009. (in Chinese) 